\title{
Substantial intraspecific variation in energy budgets: Biology or artefact?
}

\author{
Tomos Potter $^{1}$ (D) | David N. Reznick ${ }^{2}$ | Tim Coulson ${ }^{1}$ (i)
}

${ }^{1}$ Department of Zoology, University of Oxford, Oxford, UK

${ }^{2}$ Department of Evolution, Ecology and Organismal Biology, University of California, Riverside, CA, USA

\section{Correspondence}

Tomos Potter

Email: tomos.potter@zoo.ox.ac.uk

\section{Funding information}

Natural Environment Research Council; St.

John's College, University of Oxford

Handling Editor: Clelia Gasparini

\section{Abstract}

1. Dynamic energy budget (DEB) theory provides a model of the intrinsic energetic trade-offs that shape life histories, in terms of fluxes of energy through biological processes. In these models, life histories are a function of environmental conditions and of fundamental traits of the organism relating to the acquisition, allocation and use of energy.

2. These traits are described by the parameters of the DEB model, which are typically estimated from multiple data sources. DEB parameters have been estimated for over 2,500 species, and recent work has aimed to compare species on the basis of differences in parameter values. However, little is known about intraspecific variation in DEB parameters, and the reliability of comparisons between parameter sets is rarely tested.

3. We estimated DEB parameters for 16 populations of Trinidadian guppy. Our objectives were to determine whether DEB theory could characterise known lifehistory differences between populations, and to assess whether differences in parameter values between populations were reliable indicators of biological differences.

4. We found substantial intraspecific variation in parameter values. The models accurately reproduced biological processes, and also predicted differences in resource allocation and metabolic rate consistent with known life-history differences among these populations.

5. However, parameter estimates varied substantially as an artefact of the amount and types of data used to fit the models. This bias appeared to be systematic, influencing estimates for multiple populations in a comparable fashion. We show that similar patterns of growth and reproduction can be reproduced with very different parameter sets. Our results imply that comparisons of DEB parameters between models fit with different types of data may reflect artefactual rather than biological differences.

\section{KEYWORDS}

dynamic energy budget theory, ecotypes, life-history evolution, metabolic rate, Poecilia reticulata, resource allocation 


\section{1 | INTRODUCTION}

The variety of life-history strategies observed in the natural world is truly astounding. From bristlecone pine that live for millenia to mayflies that exist as adults for less than a day, evolution by natural selection has generated a vast array of solutions to life's central problem: how best to convert energy into reproductive success. Classical theory proposes that life-history evolution is driven by the interaction between (a) extrinsic ecological effects on reproduction and survival and (b) intrinsic organismal constraints, arising from trade-offs in the allocation of energy to different biological processes (Stearns, 1989, 2000). Detection of these intrinsic energetic trade-offs has been successful across taxa (Bauwens \& Díaz-Uriarte, 1997; Healy et al., 2019; Salguero-Gómez et al., 2016; Stearns, 1983), but less so within species (van Noordwijk \& de Jong, 1986). This is problematic, because intraspecific variation in (b) is a prerequisite for life-history evolution to occur. Furthermore, classical life-history theory lacks specification of 'the intra-organismal features that constrain the evolution of phenotypic traits', limiting the potential for quantitative predictions of life-history evolution (Stearns, 2013). For a mechanistic understanding of life-history evolution, a model that captures the intrinsic trade-offs involved in developing and expressing traits that underpin the acquisition, allocation and use of resources is required.

Dynamic energy budget (DEB) theory offers such a model (Kooijman, 2010). The standard DEB model describes individual life histories, derived from first principles in accordance with the constraints of thermodynamic laws (Jusup et al., 2017; Nisbet et al., 2000; Sousa et al., 2008). The model provides a single framework to describe an animal's development, growth, maintenance, reproduction and ageing, under any range of environmental conditions (Kooijman, 2010). It is important to note that the standard DEB model does not capture extrinsic factors (such as competition and predation) that shape realised life histories and drive evolution, but instead describes the intrinsic energetic trade-offs within an individual. Models are parameterised by quantifying the rates of assimilation, allocation and efficiency of energy flow between biological processes under varying levels of food availability and/or temperature (Kooijman, 2010; Kooijman et al., 2008; van der Meer, 2006). The primary parameters of the standard DEB model represent fundamental (albeit abstract) traits of individuals that, along with resource availability and temperature, determine the life history of the organism (Kooijman, 2010). DEB parameters are assumed to be individualspecific, fixed throughout life and independent of environmental conditions (except for those which are biological rates, which vary in a predictable way with temperature; Kooijman, 2010). DEB models can be parameterised with a wide range of commonly collected empirical data, and to date parameters have been estimated for over 2,500 species, covering all chordate classes (AmP, 2020; Augustine et al., 2019; Marques et al., 2018).

Differences in DEB parameter values between species are assumed to reflect evolved differences (Kooijman, 2010; Lika et al., 2020; Lika, Kearney, Freitas, et al., 2011; Marques et al., 2018). The reasoning underpinning this assumption is that the structure of the
DEB model means that parameters should covary in a simple way with maximum body size: differences in parameter values between species (accounting for differences in maximum body size) therefore indicate departures from this 'null model' and imply evolutionary adaptations of metabolic processes (Kooijman, 2010; Lika, Kearney, Freitas, et al., 2011; Marques et al., 2018). Recent work has begun to explore patterns of parameter variation across species, identifying several spectra of life-history strategies which are defined by the different ways in which species allocate energy to development, growth and reproduction (Augustine et al., 2019; Lika et al., 2019; Marques et al., 2018).

Although theory defines DEB parameters as being individualspecific, individual-level differences are considered to be sufficiently small that mean values are taken to represent species-specific parameters (Marques et al., 2018). This assumption is central to analyses of interspecific patterns of variation in DEB parameters, yet little is known about how much these parameters actually vary within species. Few studies have employed DEB theory to quantify lifehistory differences between natural populations of the same species. Marn et al. (2019) found that DEB parameters differed between Mediterranean and North Atlantic loggerhead turtles Caretta caretta, and that life-history differences between these populations could not be explained as a direct result of environmental differences between their respective habitats. In contrast, Guillaumot et al. (2020) were unable to determine differences in DEB parameters between intertidal and subtidal ecotypes of the Antarctic limpet Nacella concinna, despite clear morphological divergence. There is little consensus on the extent to which DEB parameters vary within species, or on the causes of failure to detect differences in DEB parameters between ecologically and morphologically distinct populations.

Here, we assess the extent of intraspecific variation in energy budgets of the Trinidadian guppy Poecilia reticulata. Guppies display well-characterised variation in life-history strategies, evolving distinct ecotypes in the presence or absence of predators (Reznick, 1982; Reznick \& Bryga, 1987; Reznick \& Endler, 1982). Ancestral populations of guppies live in habitats characterised by the presence of voracious predators, in particular the pike cichlid Crenicichla alta (Magurran, 2005). In several rivers, guppies have invaded further upstream, beyond barrier waterfalls which restrict the movement of large predatory fish. In these upstream habitats, guppies coexist with only one other fish species, Hart's killifish Anablepsoides hartii, which is a competitor, and also an occasional predator of guppies (Magurran, 2005). On release from intense predation pressure, these newly founded upstream guppy populations grew rapidly, until diminishing resource availability regulates population growth, driving selection for a slower life history (Bassar et al., 2013; Potter, Bassar, et al., 2021; Reznick et al., 2019). The 'low-predation' ecotype matures at larger sizes and older ages, and produces fewer, larger offspring per litter than their 'high-predation' ecotype ancestors (Reznick, 1982; Reznick \& Bryga, 1987; Reznick $\&$ Endler, 1982). The low-predation ecotype has repeatedly and independently evolved several times in Trinidad, both in natural and experimentally introduced populations (Alexander et al., 2006; 
Reznick, 1982; Reznick et al., 2019; Shaw et al., 1992; Whiting et al., 2020). As such, Trinidadian guppies provide an excellent system with which to test the ability of DEB theory to distinguish intraspecific variation in the intrinsic trade-offs that underpin life-history evolution.

In this study, we have two main objectives. The first is to determine whether DEB models can characterise well-known patterns of life-history variation among populations of Trinidadian guppies. The second is to ascertain whether parameterised DEB models reliably describe energy budgets, which would justify comparisons of species and populations by their DEB parameter values. Support for the second objective would also indicate that parameterised DEB models could play a role in broader life-history theory, by providing an appropriate model of the intrinsic energetic constraints that, together with extrinsic factors such as competition and predation risk, determine life-history evolution.

\section{2 | MATERIALS AND METHODS}

\section{1 | Overview of methods}

We estimated the parameters of the standard DEB model for 12 distinct guppy populations (three of which were sampled in multiple years), covering five independent evolutionary origins of the low-predation ecotype. According to DEB theory, differences in parameter values between populations indicate evolved differences in fundamental processes underlying the acquisition, allocation and use of energy. However, differences in parameter values may also arise from differences in data availability, that is, the types of data (e.g. growth, feeding rate, $\mathrm{O}_{2}$ consumption, etc.) and amount of data (e.g. the number of individuals measured, whether data collection covers the full life span, etc.) used to fit the models (Lika, Kearney, Kooijman, 2011). To assess this effect, we fit DEB models for four focal populations with three different levels of data availability. To identify DEB parameters associated with adaptation to resource limitation, we quantified differences in parameters between guppy ecotypes, assessing the generality of these differences across all populations fit with the same degree of data availability. Finally, we compared the variance in parameter values within Trinidadian guppies with that reported across species within the order Cyprinodontiformes.

\section{2 | The standard DEB model}

The standard DEB model (hereafter 'DEB model') describes how an organism acquires, allocates and uses energy over the course of its life, from its beginning as a fertilised egg until its death through ageing (Kooijman, 2001, 2010; Sousa et al., 2008). For a detailed description and derivations of the full model, we refer the reader to Chapter 2 of Kooijman (2010). The DEB model defines three distinct life-history stages: embryonic (no eating; no reproduction), juvenile (eating; no reproduction) and adult (eating; reproducing). An individual is characterised by four state variables: reserve, structure, maturity level and reproductive buffer (Figure 1). Reserve can be considered as stored energy, obtained through feeding, which fuels metabolic processes. Structure describes the soma of the organism and can be considered as the physical structure of the body produced and maintained through the metabolisation of reserve. The transitions between life-history stages (i.e. embryonic to juvenile; juvenile to adult) are determined by maturity level. This somewhat abstract concept captures the cumulative energy spent on developing physiological complexity, theoretically including development of the immune system (Kooijman, 2010). The reproductive buffer describes the amount of mobilised reserve that is allocated specifically to reproduction. These states vary over the life of the organism as a function of the parameters of the model (Table 1) and their interactions with environmental conditions (namely, temperature and food availability). The model captures the biological processes of feeding, assimilation of food, defecation, mobilisation of assimilated energy, allocation of mobilised energy to somatic or reproductive work, maintenance costs of somatic and reproductive work, somatic growth, attainment of maturity, reproduction and ageing (Figure 1; Tables 1 and 2). Data on the growth and reproduction of individuals at more than one level of food availability are considered sufficient

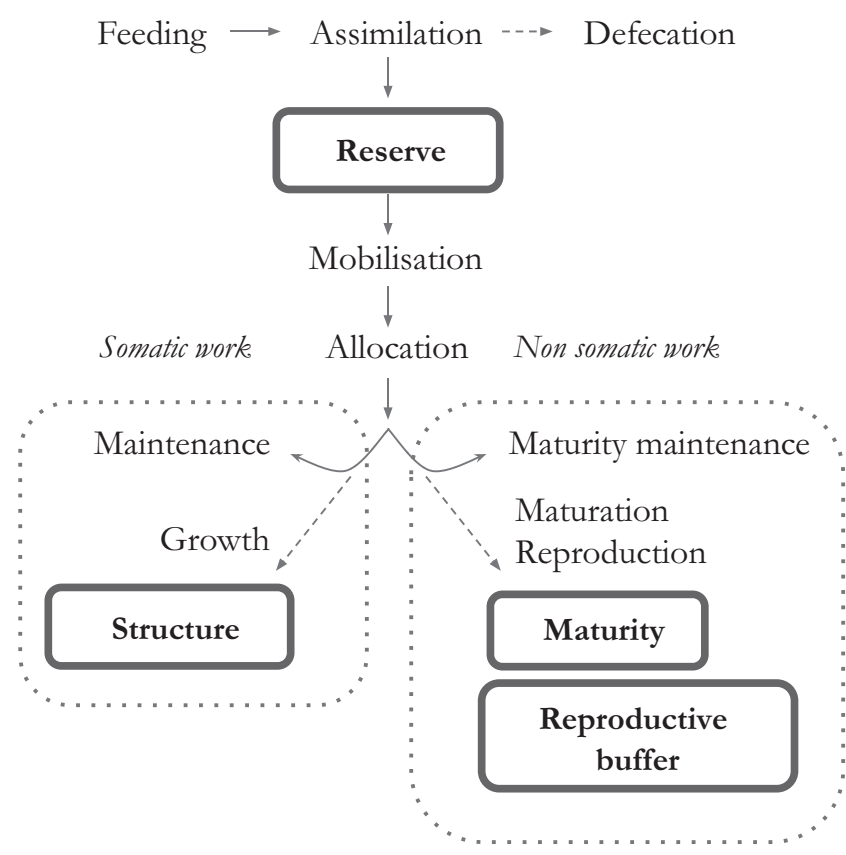

FIGURE 1 Schematic of the standard dynamic energy budget model. State variables are given in boxes, processes are shown in plain text. Processes (including ageing, not depicted) are determined by 14 parameters, described in Table 1 . Arrows represent fluxes of energy through the system via biological processes and state variables. A fraction $\kappa$ of mobilised reserve is allocated to somatic work, where somatic maintenance costs must first be met before the remainder is allocated to growth. Reserve allocated to reproductive work $(1-\kappa)$ is first used to meet maturity maintenance costs, and then used to attain sexual maturity (in juveniles) or produce offspring (in adults) 
TABLE 1 Parameters of the standard dynamic energy budget (DEB) model and the primary biological processes that they control. Two further parameters describe the shape and size of the organism: the shape coefficient $\delta_{m}$ links structural length $L$ to physical measurements of length, and the zoom factor $z$, which is the maximum structural length of the organism at ad lib food (expressed in $\mathrm{cm}$ ), allows comparisons between species of different sizes. Parameters without units are ratios, and therefore dimensionless. Symbols follow the standard DEB notation (Kooijman, 2010)

\begin{tabular}{|c|c|c|c|}
\hline Symbol & Description & Units & Process \\
\hline$\left\{\dot{F}_{m}\right\}$ & $\begin{array}{l}\text { Maximum specific } \\
\text { searching rate }\end{array}$ & $\mathrm{L}$ day $^{-1} \mathrm{~cm}^{-2}$ & Feeding \\
\hline$\left\{\dot{p}_{\mathrm{Am}}\right\}$ & $\begin{array}{l}\text { Maximum specific } \\
\text { assimilation rate }\end{array}$ & $\mathrm{J}$ day $^{-1} \mathrm{~cm}^{-2}$ & Assimilation \\
\hline$\kappa_{X}$ & $\begin{array}{l}\text { Efficiency of } \\
\text { converting food to } \\
\text { reserve }\end{array}$ & - & Defecation \\
\hline$\dot{v}$ & Energy conductance & $\mathrm{cm} / \mathrm{day}$ & $\begin{array}{l}\text { Mobilisation } \\
\text { of reserve }\end{array}$ \\
\hline$\kappa$ & $\begin{array}{l}\text { Fraction of reserve } \\
\text { allocated to somatic } \\
\text { work }\end{array}$ & - & $\begin{array}{l}\text { Allocation of } \\
\text { mobilised } \\
\text { reserve }\end{array}$ \\
\hline$\kappa_{R}$ & $\begin{array}{l}\text { Reproductive } \\
\text { efficiency (reserve } \\
\text { to egg) }\end{array}$ & - & Reproduction \\
\hline$\left[\dot{p}_{M}\right]$ & $\begin{array}{l}\text { Volume-specific } \\
\text { somatic maintenance } \\
\text { cost }\end{array}$ & $J$ day $^{-1} \mathrm{~cm}^{-3}$ & $\begin{array}{l}\text { Somatic } \\
\text { maintenance }\end{array}$ \\
\hline$\left\{\dot{p}_{T}\right\}$ & $\begin{array}{l}\text { Surface-area-specific } \\
\text { somatic maintenance } \\
\text { cost }\end{array}$ & $\mathrm{J} \mathrm{day}^{-1} \mathrm{~cm}^{-2}$ & $\begin{array}{l}\text { Somatic } \\
\text { maintenance }\end{array}$ \\
\hline$\dot{k}_{\jmath}$ & $\begin{array}{l}\text { Maturity maintenance } \\
\text { rate coefficient }\end{array}$ & day $^{-1}$ & $\begin{array}{l}\text { Maturity } \\
\text { maintenance }\end{array}$ \\
\hline$\left[E_{G}\right]$ & $\begin{array}{l}\text { Specific cost of } \\
\text { structure }\end{array}$ & $\mathrm{J} / \mathrm{cm}^{3}$ & $\begin{array}{r}\text { Somatic } \\
\text { growth }\end{array}$ \\
\hline$E_{H}^{b}$ & Maturity at birth & J & $\begin{array}{l}\text { Life-history: } \\
\text { onset of } \\
\text { feeding }\end{array}$ \\
\hline$E_{H}^{p}$ & Maturity at puberty & J & $\begin{array}{l}\text { Life-history: } \\
\text { onset of } \\
\text { allocation to } \\
\text { reproduction }\end{array}$ \\
\hline$\dot{h}_{a}$ & $\begin{array}{l}\text { Weibull ageing } \\
\text { acceleration }\end{array}$ & day $^{-2}$ & Ageing \\
\hline$S_{G}$ & $\begin{array}{l}\text { Gompertz stress } \\
\text { coefficient }\end{array}$ & - & Ageing \\
\hline
\end{tabular}

for estimation of most of the primary parameters of the DEB model (Lika, Kearney, Freitas, et al., 2011).

\section{3 | Estimating DEB parameters and predicting metabolic rate}

The majority of the data that we used to fit population-specific DEB models came from three sets of common garden experiments, in which guppies sampled from 16 populations (12 geographically and 4 temporally distinct populations) were reared at either high or low levels of food availability (Reznick et al., 2004, 2005; Reznick \& Bryga, 1996, and one unpublished dataset from D. Reznick and colleagues). Details of how these data were collected, including information on the sampled populations (location, sample size, sampling year, etc.), rearing protocols and trait measurements, are provided in the Supporting Information.

Data used to fit DEB models are of two types: zero-variate and univariate (Lika, Kearney, Kooijman, 2011). Zero-variate data are single values, whereas univariate data capture the relationship between pairs of values. For our study, zero-variate data included the mean interval between births (d) and the mean dry weight of offspring $(\mathrm{g})$, with both measures recorded at high and low food levels, and ultimate standard length $(\mathrm{cm})$ at ad lib food. Univariate data included age (days since birth) versus standard length $(\mathrm{cm})$, weight (g), cumulative reproductive output (number of offspring) and length versus weight. Each of these measures was recorded at high and low food levels. For 12 of our study populations, these data were recorded at the first three parturition events only. For four populations, data were recorded at each parturition event over the entire life span of individuals. In addition, for these four populations, we recorded mean dry weight $(\mathrm{mg})$ of neonates at high and low food, the surviving fraction of the population as a function of time since birth, daily food ration (joules per day) used in the common garden experiments (Reznick et al., 2004), and we also incorporated data on basal metabolic rate (reported as $\mathrm{O}_{2}$ consumption $[\mathrm{mg} / \mathrm{hr}]$ at $25^{\circ} \mathrm{C}$, standardised for a body weight of $74 \mathrm{mg}$ ) from an independent study using the same populations (Auer et al., 2018).

For four populations (representing two independent evolutionary origins of the low-predation guppy ecotype), more types of data were available to estimate DEB parameters than in the other 12 . To assess how the use of different types of data may affect the estimation of parameters (Lika, Kearney, Freitas, et al., 2011), we first fit DEB models for the first four populations at three different levels of data availability (Table 3 ). To compare populations across all datasets, we then fit 16 population-specific DEB models using the same level of data availability (Table 3).

Both zero-variate and univariate observations can be described as functions of primary DEB parameters, state variables, temperature and food availability. Because DEB parameters appear in multiple auxiliary models of observable relationships, model fitting is not a straightforward process. All relationships must be modelled simultaneously because no single parameter is specific to a single type of observation (Marques et al., 2019). DEB parameters are derived from theory, meaning that there are substantial constraints on their values. For example, $\kappa$, the fraction of energy allocated to somatic work, must be bounded between 0 and 1 , and the energy conductance rate $\dot{v}$ must be positive, etc. This means that parameter filters and 'psuedo-data'-parameter values that correspond to a generalised animal where the zoom factor $z=1-$ can be used to constrain the parameter space during estimation, in a manner that is analogous to the use of priors in Bayesian estimation (Lika 
TABLE 2 Linking primary parameters to biological processes in the standard dynamic energy budget (DEB) model. Formulae are summarised from table 1 in Lika and Kooijman (2011). The state variables (in red) are structural volume $V$ $\left(\mathrm{cm}^{3}\right)$, energy in the reserve $E(J)$, energy allocated to maturity $E_{H}(J)$ and energy available for reproduction $E_{R}(J)$. To simplify the presentation of equations, we also refer to two 'compound' state variables: structural length $L\left(L=V^{1 / 3}\right.$, $\mathrm{cm})$ and reserve energy density $[E]$ $\left([E]=E / V, \mathrm{~J} \mathrm{~cm}^{-3}\right)$. Primary parameters (in blue) are described in Table 1. Environmental food density $X$ is given in green. Compound parameters and state functions (in black) are defined within this table, and are functions of state variables, primary parameters and food density. Symbols follow the standard DEB notation (Kooijman, 2010). Values that are expressed per unit of structural volume are in square brackets [ ], those expressed per unit of structural surface area are in braces \{\}

\begin{tabular}{|c|c|c|}
\hline Description & Formula & Process \\
\hline Half-saturation coefficient & $K=\frac{\left\{\dot{p}_{A m}\right\}}{\kappa_{X}\left\{\dot{F}_{m}\right\}}$ & Feeding \\
\hline Scaled functional response & $\begin{array}{l}\text { if } E_{H}<E_{H}^{b} \\
f=0 \\
\text { else } f=\frac{X}{K+X}\end{array}$ & Feeding \\
\hline Assimilation flux & $\dot{p}_{A}=f\left\{\dot{p}_{A m}\right\} L^{2}$ & Assimilation \\
\hline Mobilisation flux & $\dot{p}_{C}=L^{3}[E](\dot{v} / L-\dot{r})$ & Mobilisation of energy \\
\hline Specific growth rate & $\dot{r}=\frac{\kappa[E] \dot{v} / L-\left[\dot{p}_{S}\right]}{[E] \kappa+\left[E_{G}\right]}$ & Somatic growth \\
\hline Somatic maintenance flux & $\dot{p}_{S}=\left[\dot{p}_{M}\right] L^{3}+\left\{\dot{p}_{T}\right\} L^{2}$ & Somatic maintenance \\
\hline Maturity maintenance flux & $\dot{p}_{J}=k_{J} E_{H}$ & Maturity maintenance \\
\hline Reproductive/maturity flux & $\dot{p}_{R}=(1-\kappa) \dot{p}_{C}-\dot{p}_{J}$ & $\begin{array}{l}\text { Allocation to non- } \\
\text { somatic work }\end{array}$ \\
\hline Reserve dynamics & $\frac{d}{d t} E=\dot{p}_{A}-\dot{p}_{C}$ & $\begin{array}{l}\text { Change in reserve } \\
\text { energy }\end{array}$ \\
\hline Structural dynamics & $\frac{d}{d t} V=\dot{r} V$ & $\begin{array}{l}\text { Change in structural } \\
\text { volume }\end{array}$ \\
\hline Maturity dynamics & $\begin{array}{l}\text { if } E_{H}<E_{H}^{p}, \\
\frac{d}{d t} E_{H}=\dot{p}_{R} \\
\text { else } \frac{d}{d t} E_{H}=0\end{array}$ & Maturation \\
\hline $\begin{array}{l}\text { Reproductive buffer } \\
\text { dynamics }\end{array}$ & $\begin{array}{l}\text { if } E_{H}<E_{H}^{p}, \\
\frac{d}{d t} E_{R}=0 \\
\text { else } \frac{d}{d t} E_{R}=\dot{p}_{R}\end{array}$ & Reproduction \\
\hline
\end{tabular}

et al., 2014; Lika, Kearney, Freitas, et al., 2011; Marques et al., 2019). The use of pseudo-data increases the identifiability of parameters while their influence on final parameter estimates is restricted by low weighting of pseudo-data during estimation. Parameter estimation is based on the minimisation of a symmetric-bounded loss function, using a Nelder-Mead simplex minimisation approach (Marques et al., 2019).

We estimated parameters from data using the freely available software package DEBTOoL_M (available from github.com/add-mypet/DEBtool_M, Marques et al., 2018) in MATLAB version R2020a. We used standard functions in the DEBTOOL_M package to predict the data for analyses with data availability levels 1 and 2. For analyses including data on food availability, we built a custom function, consisting of a set of differential equations which described the rates of change of the reserve, structure, maturity level, reproductive buffer and survival probability, accounting for the changes in food availability with age. We linked the changes in state variables to observations of traits via standard auxiliary theory (Kooijman, 2010). Biological rates are temperature-dependent: for all analyses, we assumed an Arrhenius temperature of 8,000 K. Some DEB parameters could not be estimated from the available data: we fixed the maximum specific searching rate $\left\{\dot{F}_{m}\right\}$ at $6.5 \mathrm{~L} \mathrm{day}^{-1} \mathrm{~cm}^{-2}$, and the reproductive efficiency $\kappa_{R}$ at 0.95 in all analyses-these are typical parameter values, and are recommended for use when no data are available for estimation (Lika, Kearney, Freitas, et al., 2011). Without information on food availability (i.e. data levels 1 and 2 ), assimilation 
TABLE 3 Types of data used to estimate dynamic energy budget parameters in this study at each level of data availability tested. For 12 population samples, we used data at availability level 1 only. For four population samples, data were available at all three levels. The asterisk * indicates that level 1 univariate data were available for measurements at the first three parturition events only, that is, 3 observation per individual. Univariate data at levels 2 and 3 were recorded at each parturition event over the full life span: mean number of observations per individual $=22(S D=8.5)$

\begin{tabular}{|c|c|c|c|}
\hline Data type & Units & $\begin{array}{l}\text { Food } \\
\text { treatment }\end{array}$ & $\begin{array}{l}\text { Data } \\
\text { level }\end{array}$ \\
\hline Interval between births & day & high, low & $1,2,3$ \\
\hline $\begin{array}{l}\text { Maximum standard } \\
\text { length }\end{array}$ & $\mathrm{cm}$ & ad lib & $1,2,3$ \\
\hline Age versus weight & day, g & high, low & $1^{*}, 2,3$ \\
\hline Age versus length & day, $\mathrm{cm}$ & high, low & $1^{*}, 2,3$ \\
\hline Length versus weight & $\mathrm{cm}, \mathrm{g}$ & high, low & $1^{*}, 2,3$ \\
\hline $\begin{array}{l}\text { Age versus cumulative } \\
\text { reproduction }\end{array}$ & day, - & high, low & $1^{*}, 2,3$ \\
\hline Dry weight at birth & $\mathrm{mg}$ & high, low & 2,3 \\
\hline $\begin{array}{l}\text { Age versus surviving } \\
\text { fraction of population }\end{array}$ & day, - & high, low & 2,3 \\
\hline $\begin{array}{l}\text { Age versus food } \\
\text { availability }\end{array}$ & day, J/day & high, low & 3 \\
\hline $\mathrm{O}_{2}$ consumption rate & $\mathrm{mg} / \mathrm{hr}$ & ad lib & 3 \\
\hline
\end{tabular}

efficiency $\kappa_{X}$ cannot be estimated: we fixed this value at 0.25 based on our estimates of $\kappa_{X}$ at data availability level 3. When we could not directly estimate $\kappa_{X}$, we quantified feeding rates by estimating the scaled functional response $f$ (Table 2 ) at high and low food levels. To achieve a better fit of the models to the data, we introduced two additional parameters: the first captured a delay in the onset of development, $T_{0}$ (measured in days) and the second was a low-food level specific assimilation efficiency $\kappa_{X_{\text {low }}}$. The parameter $T_{0}$ was included as an additive term in the auxiliary model for the interval between births only. For modelling growth, reproduction and survival at low food levels, we used $\kappa_{X_{\text {low }}}$ in place of $\kappa_{X}$ in the standard DEB model.

Although metabolic rate data $\left(\mathrm{O}_{2}\right.$ consumption) were only used to fit models with data availability level 3 (Table 3), we predicted metabolic rates from the parameter sets for each population, using the 'scaled_power' function in DEBtool_M. For these predictions, we estimated the total power (i.e. energetic flux $\mathrm{J} /$ day) expended by a guppy weighing $74 \mathrm{mg}$, at a temperature of $25^{\circ} \mathrm{C}$. We excluded assimilation power from our analyses, because our reference data were collected from guppies that had fasted for $24 \mathrm{hr}$ before measurement (Auer et al., 2018). We then converted this energetic flux into a mass flux (milligrams of $\mathrm{O}_{2}$ per hour) following standard assumptions about the chemical composition and potential $(\mathrm{J} / \mathrm{mol})$ of structure and reserve, and assuming a molar weight for $\mathrm{O}_{2}$ of $32 \mathrm{~g} /$ mol (Kooijman, 2010, Chapter 3).

Each population-specific set of formatted data and the MATLAB scripts required to estimate the parameters presented in this manuscript are available to download from the AmP online repository (AmP, 2020, see Table S1). Raw data are available from the Dryad Digital Repository http://doi.org/10.5061/dryad.qv9s4mwf1 (Potter, Reznick, et al., 2021).

\subsection{Assessing model fit and differences among parameter sets}

We assessed goodness of fit of the models to the data by calculating the mean error of the predictions relative to the data, for each set of observations used to fit the model (Marques et al., 2018). The overall fit of the model is described by the mean relative error, which is the grand mean of the relative error terms from each set of predictions and observations.

To determine whether there were significant differences in parameter sets between populations, we followed the approach described by Marn et al. (2019): we compared the fit of the model to the data when using the population-specific ('best') parameters with that when using a null-model parameter set. We compared the 'best' parameters with two null models: 'null 1', which was the parameter set of the alternative ecotype from the same stream, and 'null 2', which was the parameter set of the same ecotype from the alternative stream. This allowed us to test whether the parameter sets were distinct between (a) ancestral and derived populations in the same stream and (b) between common ecotypes that have evolved in different streams. We assessed differences in parameter sets between the four populations (two ecotype pairs) for models fit with the highest level of data availability. We tested the difference in fit of DEB parameter sets using Wilcoxon's paired rank test (Marn et al., 2019).

Finally, we assessed how intraspecific variation in DEB parameters compares with interspecific variation. Parameter values are expected to be more similar among closely related species. We compared parameter values obtained in this study for Trinidadian guppies with parameter values of other species within the order Cyprinodontiformes. We retrieved all available Cyprinodontiformes parameter sets from the AmP database (AmP, 2020; 59 species), and visualised the variation among pairs of parameters. We performed F-tests to compare intraspecific and interspecific variation in DEB parameters. Calculations were performed in the $R$ environment $(R$ Core Team, 2019), and all figures were produced using the GGPLOT2 package (Wickham, 2011).

\section{3 | RESULTS}

\section{1 | Impact of data availability on parameter estimates}

Our estimates of DEB model parameters depended on the type and amount of data used to fit the models (i.e. data availability, Table 4). Estimates of the fraction of energy allocated to somatic work $\kappa$, the 


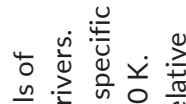

品 는

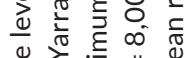

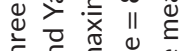

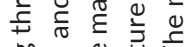

.

ज行范范

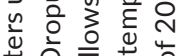

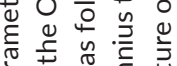

ॠ

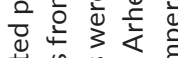

范

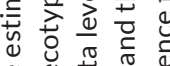

$\sum$ 造

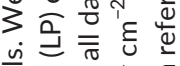

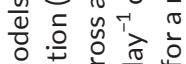

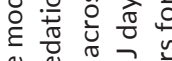

这范

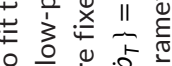

눙

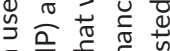

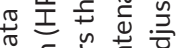

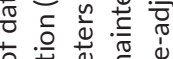

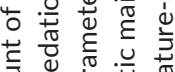

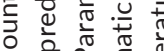

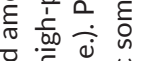

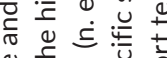

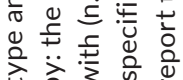

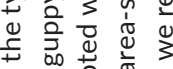

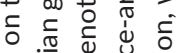

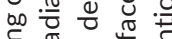

绕 䨔此

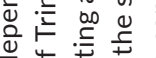

范萧。

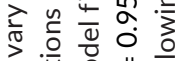

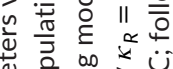

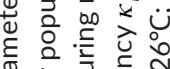

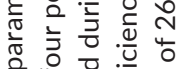

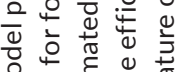

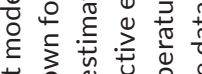

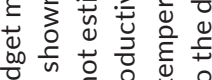

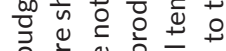

万人

के

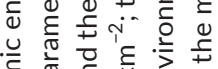

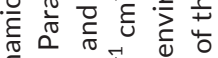

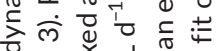

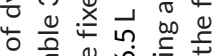

ये

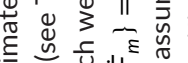

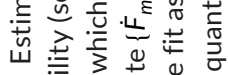

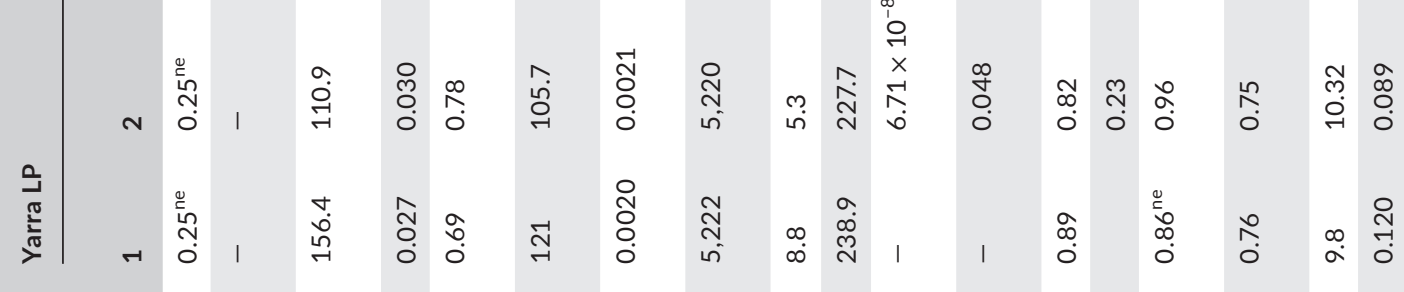

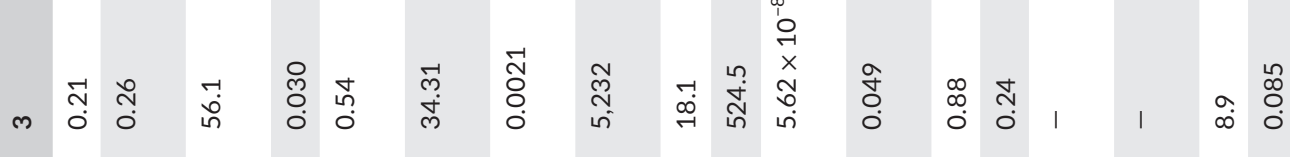

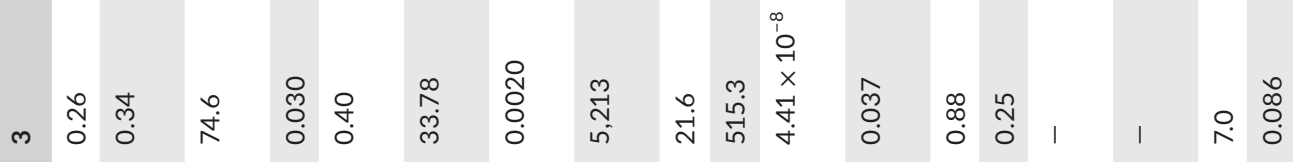

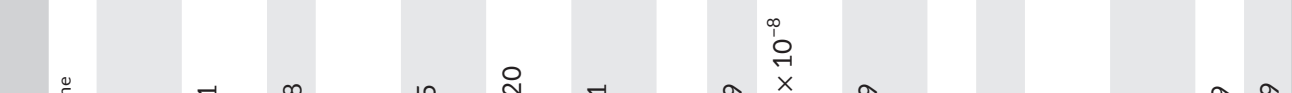

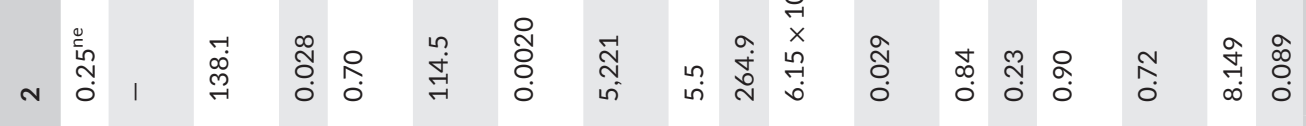

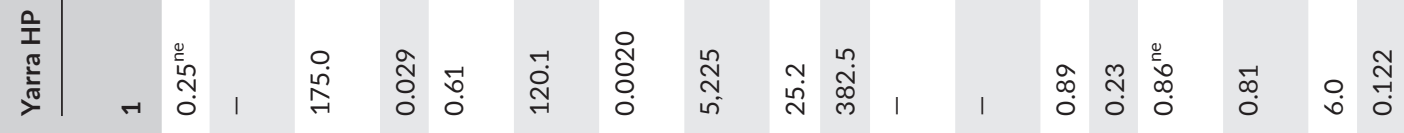

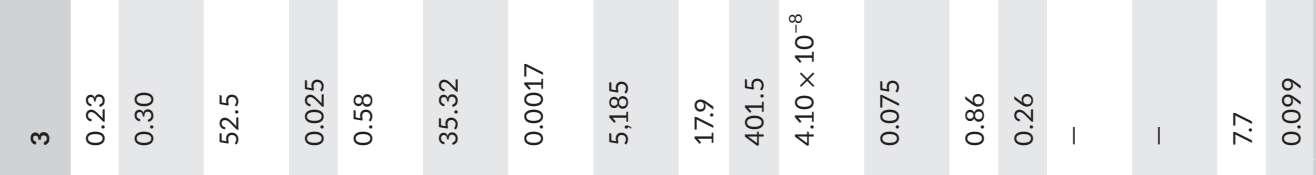

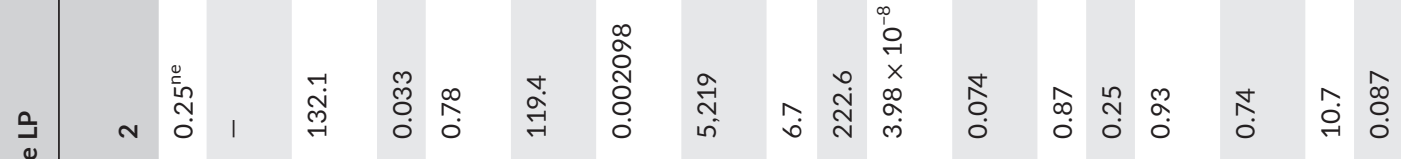

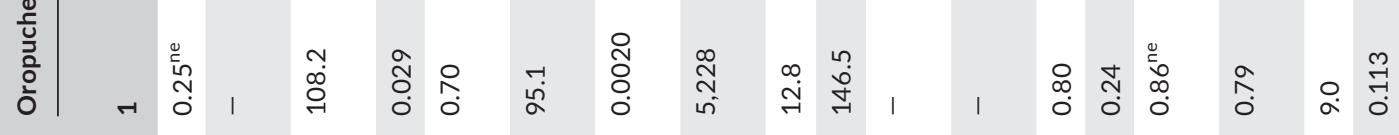

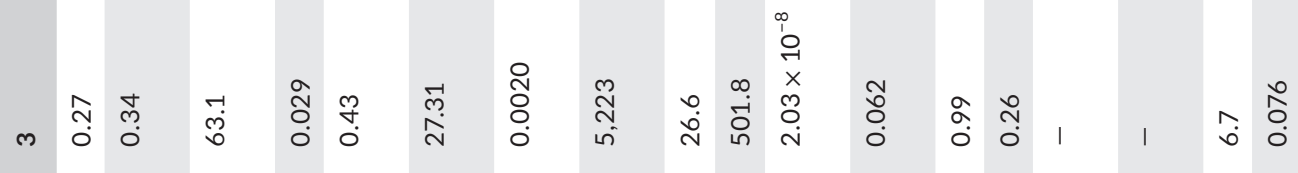

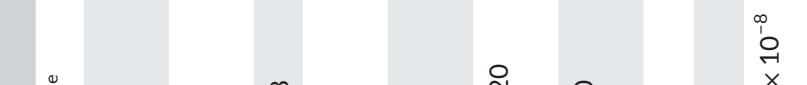

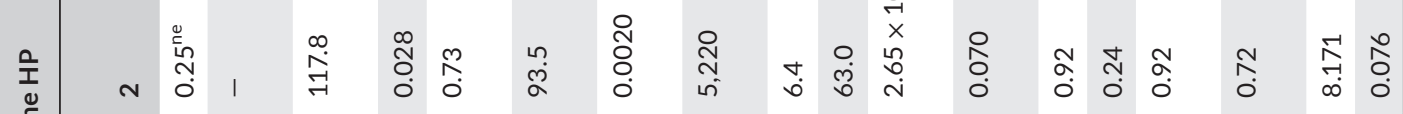

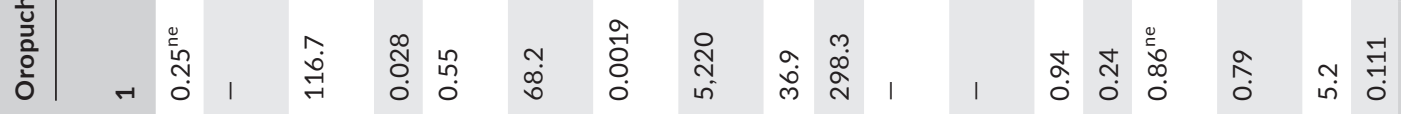

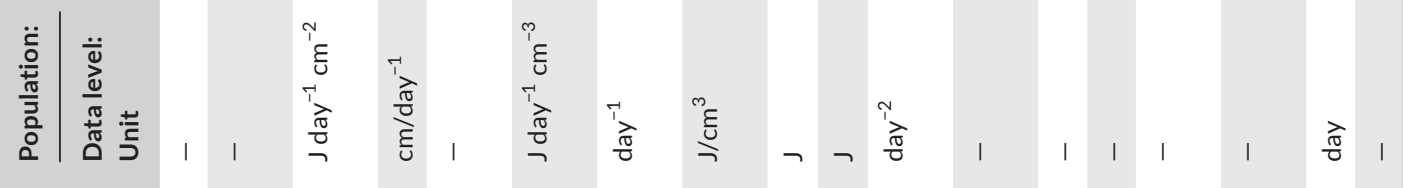

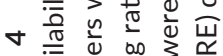

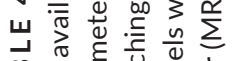

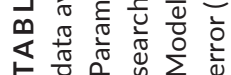

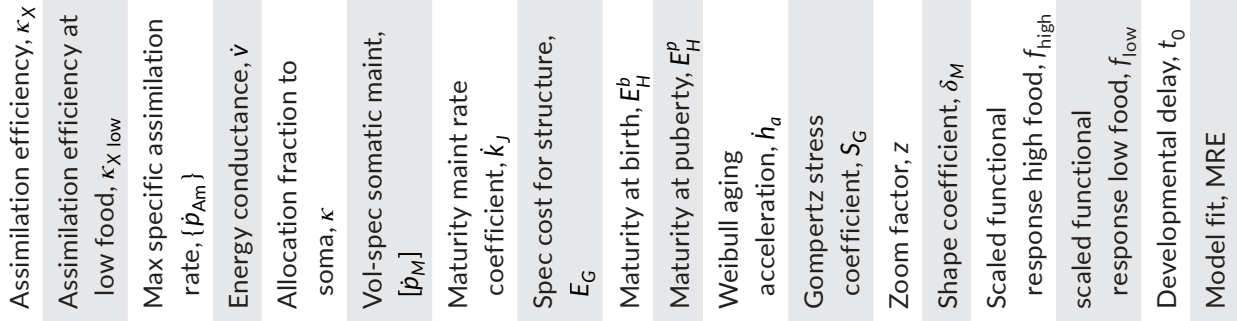


maximum assimilation rate $\left\{\dot{p}_{\mathrm{Am}}\right\}$ and of the volume-specific somatic maintenance rate $\left[\dot{p}_{M}\right]$ were all substantially lower when estimated using level 3 data. Estimates of the maturity threshold at the onset of the adult stage, $E_{H}^{p}$, were highest when estimated using level 3 data. These patterns were consistent across all four populations tested (Table 4).

Despite substantial differences in parameter values by data level, the different parameter sets were able to reproduce how standard length, mass and cumulative reproductive output changed as a function of age and food level (Figure 2), as well as predicting age and dry weight at birth (at high and low food) and maximum length (Table S2). The overall fits of the models to the data, as quantified by the mean relative error, were poorest for models fit with data level 1 , and were reasonable $(\mathrm{MRE}<0.1)$ and comparable between models fit at data levels 2 and 3 (Table 4).

\section{2 | Ecotype-specific parameter differences}

Our initial assessment of ecotype-specific differences in DEB parameters considered two ecotype pairs (four populations) for which level 3 data were available. In general, parameter sets were significantly different between populations and ecotypes: the populationspecific parameter sets gave a significantly better fit to the data compared to parameter sets from the other population (different ecotype) within the same river systems, or from the same ecotype from a different river system (Table S3). There was one exception: for data from the low-predation Oropuche population, there was no significant difference in fit when using the population-specific parameter set, or the parameter set from the low-predation Yarra population (Table S3).

Guppy ecotypes adapted to high- and low-predation-risk environments differ in how they obtain, allocate and use resources: we found that DEB parameters (estimated with level 3 data availability) differed between ecotype pairs, and that these differences were often consistent between independent evolutionary origins of ecotype pairs in the Oropuche river and Yarra rivers. (Table 4, Figure 3). Six parameters varied consistently between ecotypes: for both rivers, compared to the high-predation ecotype, low-predation guppies had lower maximum assimilation rates $\left(\left\{\dot{p}_{\mathrm{Am}}\right\}\right)$ and assimilation efficiencies $\left(\kappa_{X}\right.$ and $\kappa_{X}$ low $)$, allocated a greater fraction of available energy to somatic work $(\kappa)$, had a longer delay period at the onset of development $\left(t_{0}\right)$ and had higher values for the Gompertz stress coefficient $\left(S_{G}\right.$; Figure $\left.3 a\right)$.

The magnitude of ecotype differences was inconsistent between streams for somatic maintenance costs $\left(\left[\dot{p}_{M}\right]\right)$, the Weibull ageing acceleration parameter $\left(\dot{h}_{a}\right)$ and for maturity thresholds $\left(E_{H}^{b}\right.$ and $E_{H}^{p}$; Figure $3 b$ ). For five parameters, there were negligible differences between ecotypes, and this was consistent between streams. These parameters were the maturity maintenance coefficient $\left(k_{j}\right)$, energy conductance $(\dot{v})$, the energetic cost of structure $\left(E_{G}\right)$, the shape coefficient $\left(\delta_{m}\right)$ and the zoom factor $z$ (Figure 3c). (a)

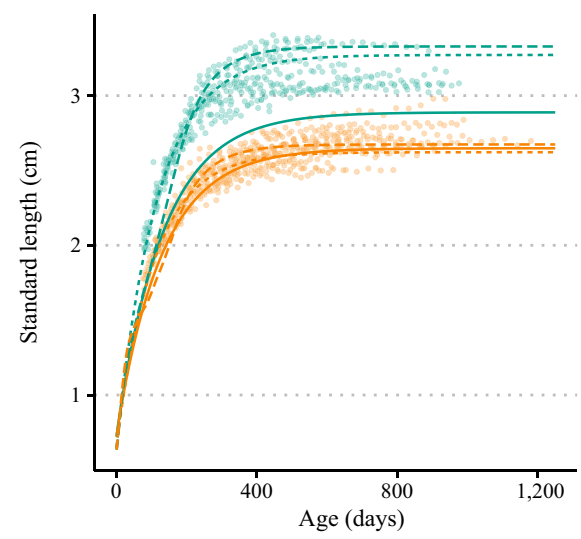

(c)

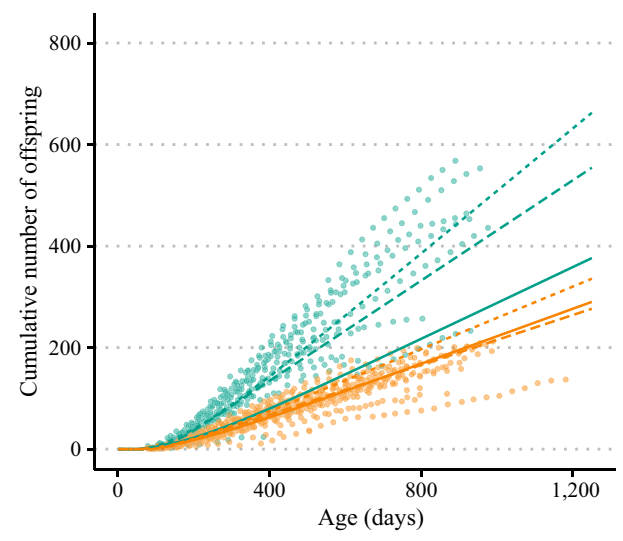

(b)

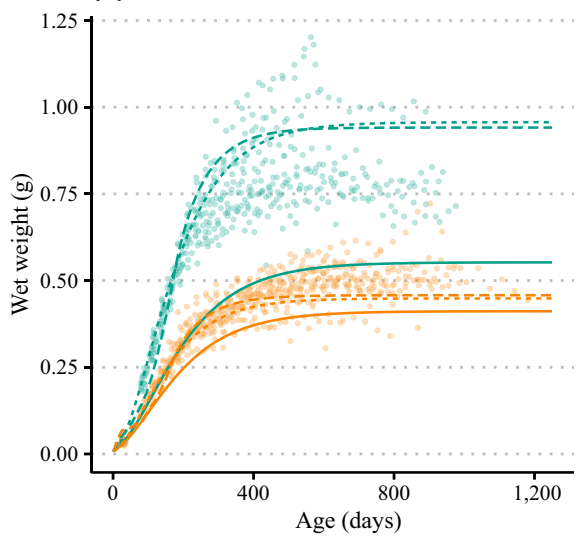

Food treatment

— High

— Low

Data level

$-1$

… 2

--. 3
FIGURE 2 Observations and predictions of (a) length, (b) weight and (c) cumulative number of offspring, as a function of age. Individual trajectories of growth and reproduction (points) and predictions (lines) are of low-predation ecotype guppies from the Oropuche River, under high (blue) and low (orange) food treatments. Lines show predictions based on different parameter sets, estimated with different levels of data availability (defined in Table 3) 
FIGURE 3 Percentage differences in dynamic energy budget parameter values for the low-predation (LP) ecotypes relative to the high-predation (HP) ecotype. Differences between ecotypes from the Oropuche are given in blue; those from the Yarra are given in yellow. Values are given for values fit at data availability levels 1 (circles), 2 (crosses) and 3 (filled circles with bars). Parameters are categorised into three groups with respect to relationships observed at data availability level 3: (a) Parameters differ between ecotypes, and the direction of the effect is consistent between streams; (b) Parameters differ between ecotypes, and the direction and/or magnitude of the effect differs between streams; and (c) parameters do not differ between ecotypes or streams. Dotted lines indicate a difference of plus or minus $20 \%$, representing the threshold used to categorise parameters as falling in A, B or C. N.B The ecotype difference of $E_{H}^{p}$ for the Oropuche at data level 2 was extreme $(+548 \%)$ and is not shown in this figure

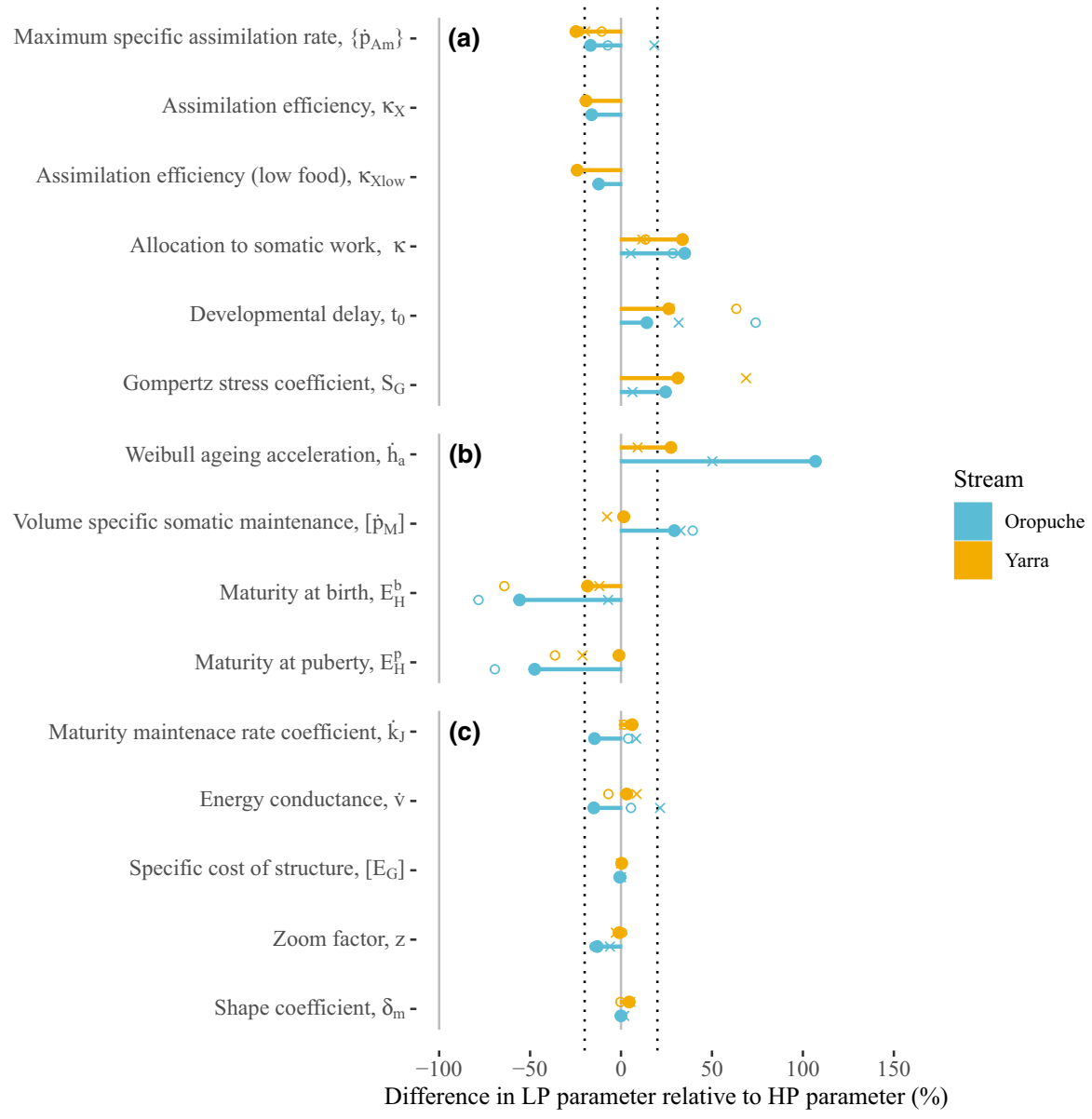

In general, the ecotype differences observed when models were fit with level 3 data availability were qualitatively similar when estimated with data levels 1 and 2 (Figure 3a). The exception was for $\left\{\dot{p}_{\mathrm{Am}}\right\}$, which followed the same trend as at data levels 2 and 3 in the Yarra river, but not in the Oropuche river (Table 4; Figure 3a). We found that parameters relating to the maturity thresholds $\left(E_{H}^{b}\right.$ and $\left.E_{H}^{p}\right)$ varied considerably by data availability and population (Table 4).

We then fit DEB models at level 1 data availability for these four populations, plus an additional 12 populations. The overall fits of the models (MRE) ranged from 0.076 to 0.137 , with a grand mean MRE of 0.107 . Full parameter sets and model fit scores are provided in Table S4. We again found that the low-predation ecotype allocated a greater fraction of energy to somatic work, and had lower maximum assimilation rates than the high-predation ecotype (Figure 4). Using the parameter sets for each population, we predicted basal metabolic rate in terms of $\mathrm{O}_{2}$ consumption rates. Note that metabolic rate data were not used to fit models at data level 1 . The low-predation ecotype was predicted to have lower rates of oxygen consumption than the high-predation ecotype (Figure 4c)-a pattern consistent with previously published work (Auer et al., 2018). However, the estimates of oxygen consumption for both ecotypes were typically about $50 \%$ greater than the values of those reported in (Auer et al., 2018), that is, the values used to fit models at level 3 in this study.

\section{3 | Intraspecific and interspecific variation}

We compared the intraspecific variation in six DEB parameters reported in this study with the interspecific variation reported within the order Cyprinodontiformes (AmP, 2020; Figure 5). The variance in $\kappa$ for Trinidadian guppies (across all data levels in this study) was comparable to that reported in 59 species within the order Cyprinodontiformes $\left(F_{23,58}=0.77, p=0.49\right)$. This variance in guppy $\kappa$ values was largely an artefact due to differences in the data levels used to fit these models. When we considered only parameters from models fit with data level 1 , the intraspecific variance in $\kappa$ across 16 populations of Trinidadian guppy was significantly less than that seen within 20 species in the family Poeciliidae $\left(F_{15,19}=0.24\right.$, $p=0.008)$. Similarly, for the five other DEB parameters $\left(\left[\dot{p}_{M}\right],\left\{\dot{p}_{A m}\right\}, \dot{v}\right.$, $E_{H}^{b}$ and $\left.E_{H}^{p}\right)$, intraspecific variation was significantly less than variation within the family Poeciliidae (F-tests, $p<0.05)$.

\section{4 | DISCUSSION}

We identified considerable variation in DEB parameters among populations of Trinidadian guppies. Although variation in DEB parameters is theoretically predicted to reflect evolved, biological differences (Kooijman, 2010; Lika et al., 2020; Lika, Kearney, Freitas, et al., 2011; Marques et al., 2018), our results suggest that 
(a)

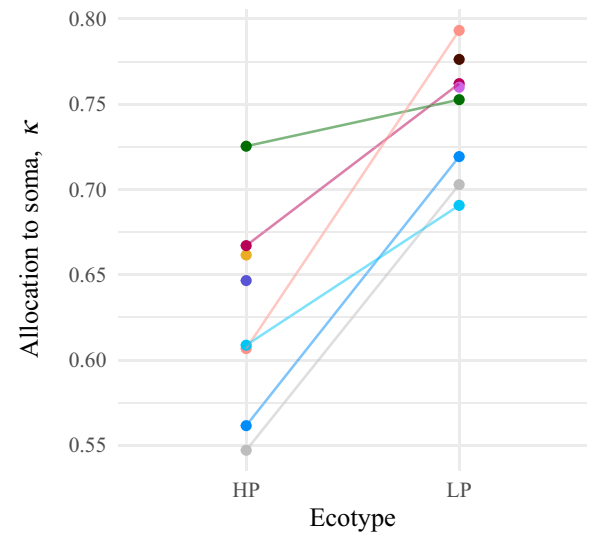

(c)

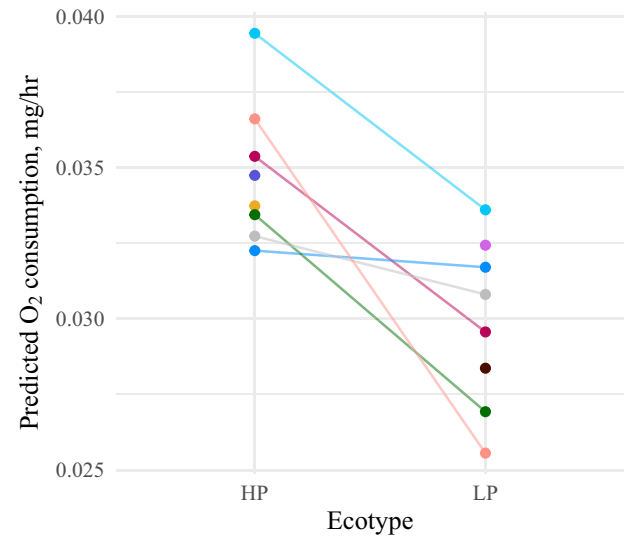

(a)

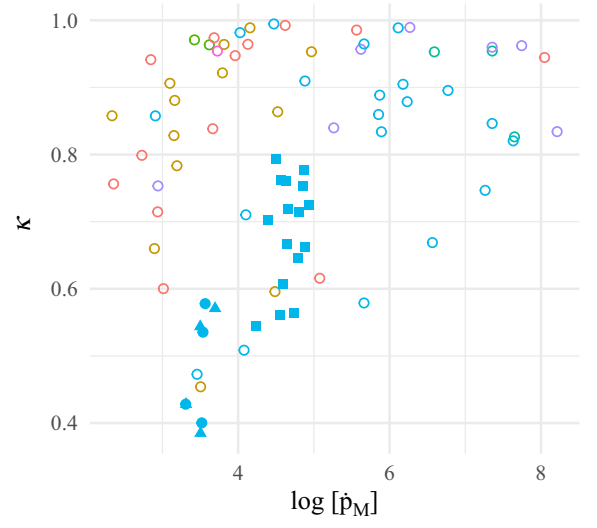

(c)

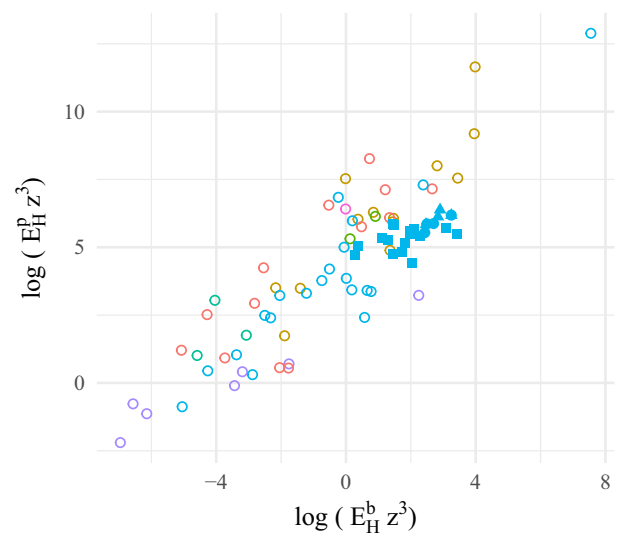

(b)

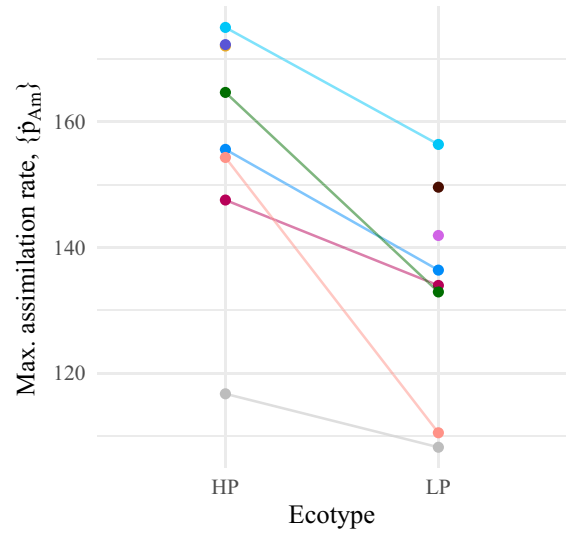

Stream

$\multimap$ Curaguate (1996) $\rightarrow$ Paria (1996)

- Madamas (1991) — Paria tributary (1996)

$\multimap$ Marianne (1991) - Yarra (1991)

$\bullet$ Marianne (1996) $\bullet$ Yarra (1996)

$\because$ Oropuche (1998) $\rightarrow$ Yarra (1998)
FIGURE 4 Differences between highpredation (HP) and low-predation (LP) ecotype populations in (a) the fraction of energy allocated to somatic work $\kappa$, (b) the maximum specific assimilation rate $\left\{\dot{p}_{\text {Am }}\right\}$ and (c) predicted basal metabolic rate (oxygen consumption) for an individual weighing $74 \mathrm{mg}$, based on the full population-specific parameter set. Parameters were estimated using level 1 data availability for 16 populations. Lines connect ecotype pairs sampled from the same stream in the same year, that is, they connect the ancestral (HP) ecotype to the derived (LP) ecotype
FIGURE 5 Comparison of intraspecific and interspecific variation in primary dynamic energy budget parameters: Pairwise plots are of (a) the fraction of reserve allocated to somatic work $\kappa$ and the volume-specific somatic maintenance cost $\left[\dot{p}_{M}\right]$, (b) the maximum specific assimilation rate $\left\{\dot{p}_{\mathrm{Am}}\right\}$ and the energy conductance $\dot{v}$, and (c) the maturity level at birth $E_{H}^{b}$ and at puberty $E_{H}^{p}$. Note that to account for parameter variation due to differences in maximum body size between species, values for $E_{H}^{b}$ and $E_{H}^{p}$ are multiplied by $z^{3}$ (Kooijman, 2010). Axes are on the log-scale, except for the $y$-axis in (a). Filled points are parameter values obtained for Trinidadian guppies in this study, using data availability at level 1 (squares), level 2 (triangles) and level 3 (circles). For details on data levels, see Table 3. Empty circles are parameter estimates for 59 species from 7 families within the order Cyprinodontiformes, obtained from the AmP online database (AmP, 2020) 
systematic bias during parameter estimation-an artefact of the type and amount of data used to fit the models-may generate substantial variation. Nevertheless, population-specific parameter sets were able to characterise known life-history variation in our study species.

\section{1 | Data type influences estimation of DEB parameters}

Fitting models with different types of data resulted in very different parameter estimates for the same populations. This variation was clearly an artefact of the estimation procedure, whereby the amount and type of data used to fit models had substantial effects on estimates of DEB parameters. For example, including data on metabolic rate and daily food availability halved estimates of the maximum rate at which energy is assimilated $\left(\left\{\dot{p}_{\text {Am }}\right\}\right)$. Estimates of $\kappa$ varied such that guppies in one population were predicted to allocate as much as $70 \%$ of available energy to somatic work, or as little as $40 \%$, depending on the type of data used to fit the models (Table 4). Do these fish invest more energy in reproduction, or in somatic growth and maintenance? Had we used a single level of data availability when fitting our models, we may have felt confident in our answer. That confidence would have been misplaced: when fitting models with different types of data, our results gave conflicting answers to this basic question of energy allocation.

When we included data only from juveniles and young adults (level 1 data, Table 3), the models attained a reasonable fit but did not accurately predict growth and reproduction of older adults (Figure 2). This suggests that greater data coverage of growth and reproduction trajectories are required to accurately predict energy budgets over the full life span. However, when models were fit with full life span data (levels 2 and 3), despite substantial differences among parameter sets, the net combination of parameter values reproduced remarkably similar patterns of growth and reproduction, reasonably fitting the observed data (Figure 2). This is an example of getting the right answer for the wrong reasons. But which reason is least wrong? The nature of a balanced energy budget means that, for example, a decrease in somatic maintenance costs must be balanced by, say, a decrease in assimilation efficiency, if patterns of growth are to remain fixed. The interactive and parameter-rich structure of the DEB model allows many possible routes through which this balance can manifest, but those routes become increasingly constrained as more different types of data are used to fit the models.

When we included data on $\mathrm{O}_{2}$ consumption and daily food availability (i.e. level 3 data availability, Table 3), estimates of several parameters changed substantially, and these changes were consistent across all four populations tested: maximum assimilation rate, the fraction of energy allocated to somatic work and somatic maintenance costs all decreased while the maturity threshold at which the adult stage is met increased (Table 4). To balance the food availability with $\mathrm{O}_{2}$ consumption rates, this required a set of parameters where less energy was assimilated from the environment; less was allocated to somatic growth; somatic overheads were reduced and more energy was invested in attaining, and also in maintaining maturity. This happened because initial fits (without using $\mathrm{O}_{2}$ consumption data) generated parameter sets that overestimated basal metabolic rate by about a half (Table S2). When the fitting process was forced to account for the measured rates of $\mathrm{O}_{2}$ consumption, the total dissipation power had to decrease: data on growth and reproduction constrained this to decreases in energy assimilation rates, with more investment in non-somatic work balanced by decreases in somatic maintenance costs, and increases in the costs of maturation. As such, in the absence of $\mathrm{O}_{2}$ consumption data, we overestimated the energetic costs of somatic maintenance by a factor of around 2, resulting in overestimation of basal metabolic rate. Note that the data on $\mathrm{O}_{2}$ consumption were measures of basal metabolic rate from a separate study to the main datasets used, whereas our predictions include the somatic costs associated with everyday activity. As such, it may be expected that predicted metabolic rates would be higher than measured basal metabolic rate. However, DEB theory assumes that energetic costs associated with routine movement are generally negligible with respect to the total energy budget (Kooijman, 2010), meaning that DEB predictions of metabolic rate should closely match measurements of basal metabolic rate. Our results could be interpreted as a violation of this assumption, which acts to modify the estimates of a suite of parameters when basal metabolic rate data are used to fit DEB models.

Does increasing data availability improve the likelihood of identifying the 'true' DEB parameters? Although in our study using level 3 data generally gave a better fit than lower levels (Table 4), and including more data during parameter estimation should reduce overfitting, we cannot rule out the possibility that parameter values at lower levels are more realistic. A confounding factor in our analyses is that the population-specific $\mathrm{O}_{2}$ consumption data came from an independent study (Auer et al., 2018). Although combining data from different studies is an appealing aspect of the DEB philosophy, and has facilitated the estimation of parameter sets for several thousand species (AmP, 2020), this approach will introduce additional sources of variation-both biological and environmental-that could reduce the reliability of parameter estimates. We suspect that somatic and maturity maintenance costs are generally poorly determined by data on reproduction and growth alone, but data on $\mathrm{O}_{2}$ consumption (from the same study that reproduction and growth data are obtained) would be needed to test this. As such, in the present analyses, we cannot determine which parameter values are closest to the 'true' values describing population-specific energy budgets.

\section{2 | Biological variation and DEB parameters}

For most parameters, differences between our four focal populations were qualitatively similar when fit with different levels of data availability (Figure 3). This suggests that the level of data availability has a systematic effect on parameter estimation, implying that comparison of populations fit with the same level of data availability 
may be valid for assessing relative (rather than absolute) differences in energy budgets. To test this, we assessed whether the DEB approach could identify and predict known life-history variation among 16 populations of Trinidadian guppies, comparing predicted responses and parameters within levels of data availability.

Our results demonstrate that life-history variation among populations of guppies can be characterised by differences in DEB parameters. Low-predation ecotype guppies allocated a greater fraction of energy to somatic work (higher values of $\kappa$ ), and had lower maximum assimilation rates (lower values of $\left\{\dot{p}_{\text {Am }}\right\}$ ) than their high-predation ecotype ancestors. These differences were consistent across 16 spatiotemporally distinct populations, representing five independent evolutionary origins of the low-predation ecotype (Figure 4). For the four populations that we were able to fit at higher levels of data availability, we also found that the low-predation ecotype was less efficient at assimilating energy (lower values of $\kappa_{X}$ ) than their high-predation counterparts (Figure 3). Population-specific parameter sets gave significantly better fits to the data than parameter sets from the other ecotype, indicating that these parameter differences reflect biological differences between ecotypes.

Apart from predicting the patterns of growth and reproduction used to fit the models, how do these differences in DEB parameters compare with known life-history variation in Trinidadian guppies? Low-predation guppies invest less in reproduction (Reznick $\&$ Endler, 1982), which corresponds with the higher values of $\kappa$ we identified here. Low-predation ecotypes also have slower metabolic rates (Auer et al., 2018)-DEB estimates of metabolic rate from all populations predicted this pattern (Figure $4 \mathrm{c}$ ), despite metabolic rate data not being used to fit these models.

A surprising result is lower rates and efficiencies of assimilation in low-predation guppies. Given that the low-predation ecotype evolves in response to reduced resource availability (Bassar et al., 2013; Potter, Bassar, et al., 2021; Reznick et al., 2019), it would appear maladaptive to evolve a reduced capacity for energy assimilation. Furthermore, low-predation guppies have increased gut length relative to the highpredation ecotype, which should facilitate higher rates of energy assimilation (Zandonà et al., 2015). However, our parameter estimates ( $\kappa_{X}$ and $\left\{\dot{p}_{\text {Am }}\right\}$ ) were specific to the high-protein diet used in the experiments. One possible explanation is that the experimental diet more closely resembled the natural diet of high-predation guppies, which are richer in high-quality invertebrate prey (Zandonà et al., 2011). Digestion of protein-rich food is energetically costly (Cho et al., 1982), and high efficiencies may not be maintained through selection in natural low-predation populations, where diets are dominated by lowquality algae and detritus (Zandonà et al., 2011). Had a lower quality diet been used in these experiments, we may have seen higher assimilation rates and efficiencies in the low-predation ecotype.

To improve model fits, we introduced two additional parameters to the standard DEB model. First, we included a second assimilation efficiency parameter, specific to the low food treatment $\kappa_{X}$ low ). Assimilation efficiencies were consistently higher in the low food treatment than they were in the high food treatment. This could indicate that in the high food treatment not all of the daily food ration was consumed, meaning that we overestimated the amount of food eaten by individuals in this group. However, a daily record of whether each fish had consumed their full ration was kept for these experiments: failure to eat the full ration was rare, and there was no systematic tendency for fish in the high food treatment to not consume full rations. A more plausible explanation is that our DEB model failed to capture how total energetic flux changed as a function of food availability in guppies. One empirical measure of energetic flux-standard metabolic rate-has been shown to increase at higher food levels (Auer et al., 2015). Although this should be captured in the DEB model-reserve density should be greater, and therefore every process downstream of the assimilation flux (Table 2 ) should have higher rates at high food levels-in our study, this difference was partially attributed to different assimilation efficiencies $\left(\kappa_{X}\right)$ at different food levels. The second introduced parameter was the developmental delay, $t_{0}$. This parameter represented a delay in the onset of development of the fertilised embryo, and was an additional term in the sub-model for the interval between births. However, there is no empirical support for such a delay in guppy development (Martyn et al., 2006). The requirement for these additional parameters in our models suggests that some assumptions of the standard DEB model-that parameters are independent of food levels, and that they are constant throughout life-may be unrealistic for guppies.

Differences in parameter values between ecotypes were not always consistent between different streams. For four parameters, the magnitude of ecotype differences varied considerably between streams (Figure 3b). Furthermore, there was substantial variation in parameter values and predicted metabolic rates within ecotypes for models fit with level 1 data (Figure 4; Table S4). Because each stream represents an independent evolutionary origin of the lowpredation ecotype, these differences may reflect alternative mechanisms through which adaptation to competitive, resource-limited environments has occurred. The distinction between guppy ecotypes is well characterised (Reznick, 1982; Reznick \& Bryga, 1987; Reznick \& Endler, 1982). However, there is substantial life-history variation among low-predation populations from different streams, including differences in rates of senescence (Reznick et al., 2004, 2005), juvenile growth rates (Arendt \& Reznick, 2005), basal metabolic rate (Auer et al., 2018), how competitive ability scales with body size (Potter et al., 2019) and in genes associated with living in a low-predation habitat (Whiting et al., 2020). Natural populations of guppies display considerable variation in organismal stoichiometry, including within ecotypes (El-Sabaawi, Kohler, et al., 2012; El-Sabaawi, Zandonà, et al., 2012): our results here support the notion that there are multiple mechanistic routes through which the low-predation ecotype can evolve.

\subsection{Implications of variation in DEB parameters}

One of the strengths of the DEB approach-that models can be fit with a wide range of data from different studies-may come at a cost 
in terms of the reliability of comparisons of parameters across species. Although the sensitivity of parameter estimation to the types of data used to fit DEB models has been noted in a simulation study (Lika, Kearney, Kooijman, 2011), we feel that the potential scale of this problem may not be generally appreciated. Our results show that variation in DEB parameters in a single species can match the variation seen across an entire order, if differences in the types of data used to fit the models are not taken into account (Figure 5a). This type of variation in estimated parameter values, which does not reflect true biological variation, is potentially problematic for studies that aim to quantify life-history strategies across taxa on the basis of DEB parameters (Augustine et al., 2019; Lika et al., 2019; Marques et al., 2018). However, if this type of data-type-dependent variation is truly systematic, as it appears to be in this study, then it may be possible to correct for differences in data type between parameter sets and improve the ability to detect such broad-scale patterns of life-history strategies.

DEB theory predicts that closely related species should share more similar parameter values, and our results support this: guppy parameters (when fit with the same data types) tended to cluster together when compared to interspecific variation in parameters (Figure 5), and intraspecific variation in guppies was significantly lower than the variation seen within the family Poeciliidae. However, in our system, ecotype pairs (i.e. high-predation and low-predation ecotypes) within a stream are more closely genetically related than two populations of the same ecotype, yet DEB parameters were more similar within ecotypes than between. Our results suggest that convergent evolution can result in similarity of DEB parameters that do not reflect genetic relatedness.

\section{5 | CONCLUSIONS}

Our objectives in this study centred around two questions: (1) Can DEB theory characterise well-known life-history variation among populations of the Trinidadian guppy? and (2) Do parameterised DEB models reliably describe energy budgets such that populations and species can be compared by the difference in their parameter values? The answer to the first question is 'yes', in that DEB models reproduced population-specific patterns of growth, development and reproduction, and qualitatively predicted known differences between guppy ecotypes in resource allocation and metabolic rate. However, the answer to the second question, at least in this study, is less clear. We showed that variation among sets of DEB parameters can result not only from biological differences (i.e. between individuals, populations or species) but also from artefacts of the parameter estimation process. Different parameter sets can generate the same biological patterns. In some instances this may not matter, for example, if the goal is to predict a biological process based on limited data. In our study, DEB models predicted $\mathrm{O}_{2}$ consumption rates reasonably well, considering that the models were fit using data only on age, weight, length and number of offspring. Furthermore, qualitative differences between parameter sets were retained at different levels of data availability, suggesting that comparisons of parameter values for models fit with the same type of data can yield information on relative differences in energy budgets between populations or species. However, the goal of mechanistic modelling is to determine the causal relationships among interacting components of a system. In the context of DEB theory, this means accurately and reliably quantifying the primary parameters of the DEB model-a feat that we did not achieve here, given the data-type dependency of estimates. Estimation of DEB parameters is not a straightforward process, but many important developments to estimation procedures have been achieved, and are ongoing (Lika et al., 2014, 2020; Lika, Kearney, Freitas, et al., 2011; Lika, Kearney, Kooijman, 2011; Marques et al., 2018, 2019). We hope that future research will establish the extent to which differences in data availability cause systematic bias in parameter estimation, and identify solutions for comparative analyses of DEB parameters. If these issues can be overcome such that DEB models accurately quantify intrinsic energetic trade-offs, DEB theory could play a key role in the development of predictive models of life-history evolution.

\section{ACKNOWLEDGEMENTS}

We thank Bas Kooijman and Dina Lika for their advice and help in fitting the DEB models, and for checking and archiving our data and MATLAB scripts. Bas Kooijamn and Joe Travis provided helpful comments on an earlier version of the manuscript. We are grateful to the associate editor and two referees for detailed comments that improved the manuscript.

\section{AUTHORS' CONTRIBUTIONS}

T.P. conceived the ideas, developed and performed the analyses, and wrote the manuscript; D.N.R. designed and performed the common garden experiments and collected the data; T.C. supervised the study and interpreted results with T.P. All authors contributed critically to the drafts and gave final approval for publication.

\section{DATA AVAILABILITY STATEMENT}

Formatted data and code are archived online and are freely available from the 'Add my Pet' (AmP) repository: https://www.bio.vu.nl/thb/ deb/deblab/add_my_pet/. Direct links to archived files are provided in Table S1 in the Supplementary Material. Raw data files are available from the Dryad Digital Repository http://doi.org/10.5061/dryad. qv9s4mwf1 (Potter, Bassar, et al., 2021).

\section{ORCID}

Tomos Potter (iD https://orcid.org/0000-0003-3201-6130

Tim Coulson (iD https://orcid.org/0000-0001-9371-9003

\section{REFERENCES}

Alexander, H. J., Taylor, J. S., Wu, S.- S.-T., \& Breden, F. (2006). Parallel evolution and vicariance in the guppy (Poecilia reticulata) over multiple spatial and temporal scales. Evolution, 60(11), 2352-2369. 
AmP. (2020). Add-my-Pet collection: The online repository for referenced data, code, and parameters on the energetics of animal species, based on the standard Dynamic Energy Budget (DEB) model. Retrieved from https://www.bio.vu.nl/thb/deb/deblab/add_my_pet/

Arendt, J. D., \& Reznick, D. N. (2005). Evolution of juvenile growth rates in female guppies (Poecilia reticulata): Predator regime or resource level? Proceedings of the Royal Society B: Biological Sciences, 272(1560), 333-337.

Auer, S. K., Dick, C. A., Metcalfe, N. B., \& Reznick, D. N. (2018). Metabolic rate evolves rapidly and in parallel with the pace of life history. Nature Communications, 9(1), 14.

Auer, S. K., Salin, K., Rudolf, A. M., Anderson, G. J., \& Metcalfe, N. B. (2015). Flexibility in metabolic rate confers a growth advantage under changing food availability. Journal of Animal Ecology, 84(5), 1405-1411.

Augustine, S., Lika, K., \& Kooijman, S. A. (2019). Altricial-precocial spectra in animal kingdom. Journal of Sea Research, 143, 27-34.

Bassar, R. D., Lopez-Sepulcre, A., Reznick, D. N., \& Travis, J. (2013). Experimental evidence for density-dependent regulation and selection on Trinidadian guppy life histories. The American Naturalist, 181(1), 25-38.

Bauwens, D., \& Díaz-Uriarte, R. (1997). Covariation of life-history traits in lacertid lizards: A comparative study. The American Naturalist, 149(1), 91-111.

Cho, C. Y., Slinger, S. J., \& Bayley, H. S. (1982). Bioenergetics of salmonid fishes: Energy intake, expenditure and productivity. Comparative Biochemistry and Physiology Part B: Comparative Biochemistry, 73(1), $25-41$.

El-Sabaawi, R. W., Kohler, T. J., Zandoná, E., Travis, J., Marshall, M. C., Thomas, S. A., Reznick, D. N., Walsh, M., Gilliam, J. F., Pringle, C., \& Flecker, A. S. (2012). Environmental and organismal predictors of intraspecific variation in the stoichiometry of a neotropical freshwater fish. PLoS ONE, 7(3).-https://doi.org/10.1371/journal.pone.0032713

El-Sabaawi, R. W., Zandonà, E., Kohler, T. J., Marshall, M. C., Moslemi, J. M., Travis, J., López-Sepulcre, A., Ferriére, R., Pringle, C. M. Thomas, S. A., Reznick, D. N., \& Flecker, A. S. (2012). Widespread intraspecific organismal stoichiometry among populations of the Trinidadian guppy. Functional Ecology, 26(3), 666-676. https://doi. org/10.1111/j.1365-2435.2012.01974.x

Guillaumot, C., Saucède, T., Morley, S. A., Augustine, S., Danis, B., \& Kooijman, S. (2020). Can DEB models infer metabolic differences between intertidal and subtidal morphotypes of the Antarctic limpet Nacella concinna (Strebel, 1908)? Ecological Modelling, 430, 109088. https://doi.org/10.1016/j.ecolmodel.2020.109088

Healy, K., Ezard, T. H., Jones, O. R., Salguero-Gómez, R., \& Buckley, Y. M. (2019). Animal life history is shaped by the pace of life and the distribution of age-specific mortality and reproduction. Nature Ecology and Evolution, 3(8), 1217-1224.

Jusup, M., Sousa, T., Domingos, T., Labinac, V., Marn, N., Wang, Z., \& Klanjšček, T. (2017). Physics of metabolic organization. Physics of Life Reviews, 20, 1-39.

Kooijman, S. A. (2001). Quantitative aspects of metabolic organization: A discussion of concepts. Philosophical Transactions of the Royal Society B: Biological Sciences, 356(1407), 331-349.

Kooijman, S. A. L. M. (2010). Dynamic energy budget theory for metabolic organisation. Cambridge University Press.

Kooijman, S. A. L. M., Sousa, T., Pecquerie, L., Van Der Meer, J., \& Jager, T. (2008). From food-dependent statistics to metabolic parameters, a practical guide to the use of dynamic energy budget theory. Biological Reviews, 83(4), 533-552.

Lika, K., Augustine, S., \& Kooijman, S. A. (2019). Body size as emergent property of metabolism. Journal of Sea Research, 143, 8-17.

Lika, K., Augustine, S., \& Kooijman, S. A. (2020). The use of augmented loss functions for estimating dynamic energy budget parameters. Ecological Modelling, 428, 109110
Lika, K., Augustine, S., Pecquerie, L., \& Kooijman, S. A. (2014). The bijection from data to parameter space with the standard DEB model quantifies the supply-demand spectrum. Journal of Theoretical Biology, 354, 35-47.

Lika, K., Kearney, M. R., Freitas, V., van der Veer, H. W., van der Meer, J., Wijsman, J. W., Pecquerie, L., \& Kooijman, S. A. (2011). The 'covariation method' for estimating the parameters of the standard Dynamic Energy Budget model I: Philosophy and approach. Journal of Sea Research, 66(4), 270-277. https://doi.org/10.1016/j. seares.2011.07.010

Lika, K., Kearney, M. R., \& Kooijman, S. A. L. M. (2011b). The 'covariation method' for estimating the parameters of the standard Dynamic Energy Budget model II: Properties and preliminary patterns. Journal of Sea Research, 66, 278-288. https://doi.org/10.1016/j. seares.2011.09.004

Lika, K., \& Kooijman, S. A. (2011). The comparative topology of energy allocation in budget models. Journal of Sea Research, 66(4), 381-391.

Magurran, A. E. (2005). Evolutionary ecology: The Trinidadian guppy. Oxford University Press.

Marn, N., Jusup, M., Catteau, S., Kooijman, S. A., \& Klanjšček, T. (2019). Comparative physiological energetics of Mediterranean and North Atlantic loggerhead turtles. Journal of Sea Research, 143, 100-118.

Marques, G. M., Augustine, S., Lika, K., Pecquerie, L., Domingos, T., \& Kooijman, S. A. (2018). The AmP project: Comparing species on the basis of dynamic energy budget parameters. PLoS Computational Biology, 14(5), e1006100.

Marques, G. M., Lika, K., Augustine, S., Pecquerie, L., \& Kooijman, S. A. (2019). Fitting multiple models to multiple data sets. Journal of Sea Research, 143, 48-56.

Martyn, U., Weigel, D., \& Dreyer, C. (2006). In vitro culture of embryos of the guppy, Poecilia reticulata. Developmental Dynamics, 235(3), 617-622.

Nisbet, R. M., Muller, E. B., Lika, K., \& Kooijman, S. A. L. M. (2000). From molecules to ecosystems through dynamic energy budget models. Journal of Animal Ecology, 69, 913-926.

Potter, T., Bassar, R. D., Bentzen, P., Ruell, E. W., Torres-Dowdall, J., Handelsman, C. A., Ghalambor, C. K., Travis, J., Reznick, D. N., \& Coulson, T. (2021). Environmental change, if unaccounted, prevents detection of cryptic evolution in a wild population. The American Naturalist, 197(1), 29-46. https://doi.org/10.1086/711874

Potter, T., King, L., Travis, J., \& Bassar, R. D. (2019). Competitive asymmetry and local adaptation in Trinidadian guppies. Journal of Animal Ecology, 88(2), 330-342.

Potter, T., Reznick, D. N., \& Coulson, T. (2021). Data used in the study: 'Substantial intraspecific variation in energy budgets: Biology or artefact?'. Dryad Digital Repository, https://doi.org/10.5061/dryad. qv9s4mwf1

R Core Team. (2019). A language and environment for statistical computing. R Foundation for Statistical Computing. Retrieved from https:// www.R-project.org

Reznick, D. (1982). The impact of predation on life-history evolution in Trinidadian guppies - genetic-basis of observed life-history patterns. Evolution, 36(6), 1236-1250.

Reznick, D. N., Bassar, R. D., Handelsman, C. A., Ghalambor, C. K., Arendt, J., Coulson, T., Potter, T., Ruell, E. W., Torres-Dowdall, J., Bentzen, P., \& Travis, J. (2019). Eco-evolutionary feedbacks predict the time course of rapid life-history evolution. The American Naturalist, 194(5), 671-692.

Reznick, D., Bryant, M., \& Holmes, D. (2005). The evolution of senescence and post-reproductive lifespan in Guppies (Poecilia reticulata). PLoS Biology, 4(1), e7.

Reznick, D. N., Bryant, M. J., Roff, D., Ghalambor, C. K., \& Ghalambor, D. E. (2004). Effect of extrinsic mortality on the evolution of senescence in guppies. Nature, 431(7012), 1095-1099. 
Reznick, D. N., \& Bryga, H. (1987). Life-history evolution in guppies (Poecilia reticulata). 1. Phenotypic and genetic changes in an introduction experiment. Evolution, 41(6), 1370-1385.

Reznick, D. N., \& Bryga, H. A. (1996). Life-history evolution in guppies (Poecilia reticulata: Poeciliidae).5. Genetic basis of parallelism in life histories. The American Naturalist, 147(3), 339-359.

Reznick, D., \& Endler, J. A. (1982). The impact of predation on life history evolution in Trinidadian guppies (Poecilia reticulata). Evolution, 36(1), 160.

Salguero-Gómez, R., Jones, O. R., Jongejans, E., Blomberg, S. P., Hodgson, D. J., Mbeau-Ache, C., Zuidema, P. A., De Kroon, H., \& Buckley, Y. M. (2016). Fast-slow continuum and reproductive strategies structure plant life-history variation worldwide. Proceedings of the National Academy of Sciences of the United States of America, 113(1), 230-235.

Shaw, P. W., Carvalho, G. R., Seghers, B. H., \& Magurran, A. E. (1992). Genetic consequences of an artificial introduction of guppies (Poecilia reticulata) in N. Proceedings: Biological Sciences, 248(1322), 111-116.

Sousa, T., Domingos, T., \& Kooijman, S. A. (2008). From empirical patterns to theory: A formal metabolic theory of life. Philosophical Transactions of the Royal Society B: Biological Sciences, 363(1502), 2453-2464.

Stearns, S. C. (1983). The influence of size and phylogeny on patterns of covariation among life-history traits in the mammals. Oikos, 41(2), 173.

Stearns, S. C. (1989). Trade-offs in life-history evolution. Functional Ecology, 3(3), 259.

Stearns, S. C. (2000). Life history evolution: Successes, limitations, and prospects. Naturwissenschaften, 87(11), 476-486.

Stearns, S. C. (2013). Does impressive progress on understanding mechanisms advance life history theory? In T. Flatt \& A. Heyland (Eds.), Mechanisms of life history evolution, chapter 27 (pp. 364-374). Oxford University Press.

van der Meer, J. (2006). An introduction to Dynamic Energy Budget (DEB) models with special emphasis on parameter estimation. Journal of Sea Research, 56(2), 85-102. van Noordwijk, A. J., \& de Jong, G. (1986). Acquisition and allocation of resources: Their influence on variation in life history tactics. The American Naturalist, 128(1), 137-142.

Whiting, J. R., Paris, J. R., van der Zee, M. J., Parsons, P. J., Weigel, D., \& Fraser, B. A. (2020). Drainage-structuring of ancestral variation and a common functional pathway shape limited genomic convergence in natural high- and low-predation guppies. bioRxiv, 2020.10.14.339333.

Wickham, H. (2011). ggplot2. Wiley Interdisciplinary Reviews: Computational Statistics, 3(2), 180-185.

Zandonà, E., Auer, S. K., Kilham, S. S., Howard, J. L., López-Sepulcre, A., O'Connor, M. P., Bassar, R. D., Osorio, A., Pringle, C. M., \& Reznick, D. N. (2011). Diet quality and prey selectivity correlate with life histories and predation regime in Trinidadian guppies. Functional Ecology, 25(5), 964-973.

Zandonà, E., Auer, S. K., Kilham, S. S., \& Reznick, D. N. (2015). Contrasting population and diet influences on gut length of an omnivorous tropical fish, the Trinidadian guppy (Poecilia reticulata). PLoS ONE, 10(9), e0136079.

\section{SUPPORTING INFORMATION}

Additional supporting information may be found online in the Supporting Information section.

How to cite this article: Potter, T., Reznick, D. N., \& Coulson, T. (2021). Substantial intraspecific variation in energy budgets: Biology or artefact? Functional Ecology, 35, 1693-1707. https://doi.org/10.1111/1365-2435.13847 